\title{
Do Pre-service Elementary School Teachers Still Have Mathematics Anxiety? Some Factors and Correlates
}

\author{
Algumas considerações sobre a ansiedade relativa à Matemática em futuros \\ professores da escola elementar
}

\author{
Hakan Çatlığlu* \\ Ramazan Gürbüz ${ }^{* *}$ \\ Osman Birgin ${ }^{* * *}$
}

\begin{abstract}
This study aims to provide new evidence from Turkish pre-service elementary school (PES) teachers and to identify some correlations and factors associated with mathematics anxiety (MA). 480 Turkish PES teachers participated in this study. Data was collected using a Personal Information Form, Mathematics Anxiety Scale, and Mathematics Attitude Scale. Data was analyzed using the SPSS 17.0 statistics program. It was revealed that the MA level of the participants was low, and the difference based on gender was not significant. Cross-sectional comparison indicated that freshmen were more inclined to have MA than the seniors. Based on self-reported perceptions, we found that there were significant differences related to mathematics. There was a tendency for participants with negative attitudes towards mathematics and low achievers to possess higher levels of MA. It was also found that there was a significant correlation among mathematics anxiety, mathematics achievement, and mathematics attitudes. This study will provide some guidance for the revision of course requirements and teaching strategies, and promotes collaboration between mathematics educators and counselors.
\end{abstract}

Keywords: Mathematics anxiety. Pre-service elementary school teacher. Mathematics attitudes. Gender. Achievement.

\section{Resumo}

O artigo pretende investigar, no contexto da Turquia, fatores associados à ansiedade em relação à Matemática, tendo como sujeitos futuros professores da escola elementar. Quatrocentos e oitenta sujeitos compuseram a amostragem da pesquisa, cujos dados foram coletados por meio de questionários, organizados usando escalas que levaram em conta tanto a ansiedade quanto a atitude de cada sujeito em relação à Matemática e analisados usando o programa estatístico SPSS 17.0. Observou-se que o nível de ansiedade dos professores é baixo e que a diferença entre os gêneros não é significativa. Uma análise cruzada revelou que a ansiedade dos futuros professores em início de formação são mais inclinados à ansiedade que aqueles ao final do curso. A partir de relatos dos próprios participantes, foram detectadas diferenças significativas, entre eles, no que diz respeito à Matemática e a existência de uma correlação entre a ansiedade, atitudes e resultados obtidos pelos estudantes. Os

\footnotetext{
" PhD in Mathematics Education at Karadeniz Technical University, Turkey. Assistant Professor of Dicle University, Faculty of Education. Postal address: Dicle University, Ziya Gokalp Faculty of Education, Department of Secondary Science and Mathematics Education, Diyarbakır, Turkey. E-mail: hcatlioglu@gmail.com

${ }^{* *} \mathrm{PhD}$ in Mathematics Education at Karadeniz Technical University, Turkey. Associate Professor of Adiyaman University, Faculty of Education. Postal address: Adiyaman University, Faculty of Education, Department of Elementary Education, Adiyaman, Turkey. E-mail: rgurbuz@adiyaman.edu.tr

*** $\mathrm{PhD}$ in Mathematics Education at Karadeniz Technical University, Turkey. Associate Professor of Usak University, Faculty of Education. Corresponding author: Postal address: Usak University, Faculty of Education, Department of Elementary Education, 64200 Usak, Turkey. E-mail: osman.birgin@usak.edu.tr.
} 
resultados deste estudo permitem uma revisão nas exigências e estratégias de ensino dos cursos formadores, e promove a colaboração entre educadores matemáticos e orientadores educacionais.

Palavras-chave: Ansiedade. Formação de professores para a escola elementar. Atitudes. Gênero. Educação Matemática.

\section{Introduction}

Prior negative experiences with mathematics can strongly influence the students' future. Additionally, teachers and parents often impose their personal views and feelings related to the subject, including the negative ones; as a result, they may unintentionally pass these negative beliefs to the students, which may cause or increase mathematics anxiety (MA) (BALOĞLU; KOÇAK, 2006; BEKDEMIR, 2007; BUHLMAN; YOUNG, 1982; HADFIELD; MCNEIL, 1994; ROSSNAN, 2006). Therefore, MA is a very common problem among college and university students (MALINSKY; ROSS; PANNELLS; MCJUNKIN, 2006). In addition to being one of the more intensely and consistently investigated concepts in mathematics education, it has influenced many aspects of this matter, directly or indirectly. Conversely, there is no general consensus among researchers, not only about the MA's definition and dimensions, but also on its causes and effects. Vinson (2001) characterized MA as an exceeding dislike toward mathematics. It was claimed that feelings of anxiety can lead to panic, tension, helplessness, fear, distress, shame, inability to cope, sweaty palms, nervous stomach, difficulty breathing, and loss of the ability to concentrate (POSAMENTIER; STEPELMAN, 1990). To a certain extent, the anxiety may result in some positive effects, such as a stimulating force to perform well, but in academic terminology, MA is considered a debilitating problem (ZASLAVSKY, 1994). Richardson and Suinn (1972) defined MA as "[...] feelings of tension and anxiety that interfere with the manipulation of numbers and the solving of mathematical problems in a wide variety of ordinary life and academic situations" (p. 551). Byrd (1982), however, accepted this definition as deficient both from the point of view of the conceptualization of mathematics and also from the conceptualization of anxiety perspectives. Thus, it should be regarded from a larger perspective as a complex construct of an "affective, behavioral, and cognitive response to a perceived threat to self-esteem, which occurs as a response to the situations involving mathematics" (ATKINSON, 1988, p. 18).

Attitude and anxiety are firm constructs that are difficult to change, and their negative consequences, including the avoidance of the subject, distress, and interference with conceptual thinking and memory processes, may affect adult life (NEWSTEAD, 1998). Although attitudes and MA are related, they are different constructs. Byrd (1982) handled 
attitudes toward mathematics (e.g., perceived usefulness and math as a male domain) as a dispositional antecedent of MA. She separated them based upon their initial components. For attitudes, the cognitive component is primary; for anxiety the cognitive component is secondary and the emotional component is primary. Bessant (1995) considered the matter from a different perspective and argued that MA "is seen as more intense, shorter in duration, and negative," but mathematics attitudes "represent long-term dispositions that are relatively small in magnitude and either positive or negative in direction" (p. 329).

According to Hilton (1980), the defects of elementary mathematics education help spread MA. Although elementary school teachers have an important role in motivating students to develop positive attitudes towards mathematics and in creating an excitement to learn this subject, they can recognize it as being threatening and frustrating, due to their negative experiences during their own studentship. In their study, Widmer and Chavez (1982) found that approximately $16 \%$ of the elementary school mathematics teachers were math anxious. Martinez (1987) argued that MA begins with the arithmetic teacher. The quality of mathematics instruction in elementary schools was found to be related to how thorough the preparation of a PES teacher was (BATTISTA, 1986). As Franz (2005) argued, MA studies focused more on the PES teachers. Kelly and Tomhave (1985) reported that elementary education majors' anxiety levels are the highest ones when compared to four other mathanxious college groups. The teachers' attitudes may influence their students' attitudes which in turn may affect their performance and success. According to the results of 151 studies exploring MA by meta-analysis, Hembree (1990) stated that MA has been linked to poor performance in mathematics achievement tests, to the avoidance of the subject, as well as to attitudes toward mathematics. He found that pre-service arithmetic teachers' ability, grade level, and undergraduate fields of study, especially those prone to mathematics anxiety, demonstrated different MA levels.

Jackson and Leffingwell (1999) investigated the types of instructor behaviors that caused MA in students from kindergarten through college. Their survey included 157 students enrolled in a senior level elementary mathematics class who were required to teach first through sixth grades. They asked the students about their worst or most challenging mathematics classroom experiences from kindergarten through college. Of the 157 respondents, 146 (93\%) reported problems with MA. Their findings were similar to the previous studies; $16 \%$ of them had their first traumatic encounter as early as in the $3^{\text {rd }}$ and $4^{\text {th }}$ grades. 
Many studies underline the significance of the elementary mathematics classroom as the starting point of MA (HARPER; DAANE, 1998; BİRGİN; BALOĞLU; ÇATLIOĞLU; GÜRBÜZ, 2010). Uusimaki and Nason (2004) examined the causes of MA in an interview study of 18 third-year Australian pre-service elementary teachers. The findings revealed that MA could be attributed to their elementary school experiences. They analyzed their negative experiences and found that instead of specific mathematical content or social factors, such as family and peers, the elementary school teacher (72\%) was a major reason for these negative experiences. On the other hand, the teacher candidates were expected to lessen their degree of MA with the help of education provided during their pre-service education.

The results of the Program for International Student Assessment Project (PISA) revealed that the Turkish students generally felt MA. Furthermore, their mean MA score was higher than the mean score of students living in the Organization of Economic Cooperation and Development (OECD) countries (ERDD, 2005). In 2004, the Turkish primary school mathematics curriculum was renewed, based on student-centered approaches, including constructivist learning and the multiple intelligence theory. Moreover, the new Turkish mathematics curriculum took MA into consideration for the first time (MoNE, 2005). Based on the views of 247 elementary school teachers, Halat (2007) found that the new curriculum had a positive impact on the students' attitude toward mathematics.

This study aims to determine the level of MA among PES teachers by providing new evidence from Turkey, and seeks to identify some components and factors associated with MA. Determining the MA level of the PES teachers and identifying some correlation and factors associated with MA is a crucial issue, not only for the purpose of counseling or treatment, but also for a beneficial and efficient education. Current measures related to MA will reflect on the recent changes in a better way and call for different issues to be addressed in the case of MA. The results will contribute to evaluating pre-service education. Concurrently, the results will contribute to MA literature, as this study examines several factors and correlation thought to be influential or important to MA. This study attempted to answer the following questions:
a) What are the mathematics anxiety levels of Turkish PES teachers?
b) Are there any significant differences between mathematics anxiety and social factors (gender and class level), perceived importance of subjects taught in mathematics courses (PIM), perceived ability level to learn mathematics (PAM), perceived success level in mathematics (PSM), education levels of parents, family income, location of hometown, and mathematics achievement? 
c) Is there a significant relationship between MA and both mathematics achievement and mathematics attitudes?

\section{Method}

\subsection{Participants}

The study's sample consisted of 480 PES teachers. As seen in Table 1, of the 480 volunteer participants, 244 (50.8\%) were females and 236 (49.2\%) were males. A crosssectional design was used to evaluate the present pre-service education from the MA perspective. There were $232(48.3 \%)$ graduating seniors and 248 (51.7\%) freshmen completing their first year. The participants seemed to represent the culture and socioeconomic status of a suburban community. A considerably high percent of participants have low family income and, nearly half of the participants' hometowns were cities. Only a very small portion of the participants' mothers $(2.9 \%)$ had a higher education diploma or its equivalent. The education levels of fathers were somewhat better with $15.4 \%$ of them holding a higher education diploma.

Table 1 - Some characteristics of Turkish PES teachers $(n=480)$

\begin{tabular}{|c|c|c|c|c|c|}
\hline Variable & $f$ & $\%$ & Variable & $f$ & $\%$ \\
\hline Gender & & & Education Level of $M c$ & & \\
\hline Male & 236 & 49.2 & Illiterate & 124 & 25.8 \\
\hline Female & 244 & 50.8 & Primary School & 245 & 51.0 \\
\hline Class Level & & & Secondary School & 44 & 9.2 \\
\hline Freshman & 248 & 51.7 & High School & 53 & 11.0 \\
\hline Senior & 232 & 48.3 & Higher Education & 14 & 2.9 \\
\hline Family Income & & & Education Level of $F a$ & & \\
\hline Low $(<750 \mathrm{TL})$ & 266 & 55.4 & Illiterate & 24 & 5.0 \\
\hline Moderate (750-1500TL) & 135 & 28.1 & Primary School & 200 & 41.7 \\
\hline $\operatorname{High}(>1500 \mathrm{TL})$ & 79 & 16.5 & Secondary School & 63 & 13.1 \\
\hline Location of Hometown & & & High School & 119 & 24.8 \\
\hline Village & 114 & 23.8 & Higher Education & 74 & 15.4 \\
\hline Town & 142 & 29.6 & & & \\
\hline City & 224 & 46.7 & & & \\
\hline
\end{tabular}

Source: developed by the authors

\subsection{Instruments}

The instruments used in this study consisted of the Mathematics Anxiety Scale toward Teacher Candidate (MAST) (ÜLDAŞ, 2005), Mathematics Attitude Scale (AŞKAR, 1986), and a Personal Information Form. 
Mathematics Anxiety Scale toward Teachers and Teacher Candidates (MAST): This instrument is composed of a 39 5-Likert type item scale to assess MA and it was developed by Üldaş (2005). It consisted of seven sub-scales, which explained $59.23 \%$ of the total variance. Five hundred and two teachers and 1066 teacher candidates were involved in the reliability and validity studies of the scale. Üldaş (2005) reported the Cronbach alpha coefficient to be .95 , for the reliability of the measurements of the MAST scale. Cronbach alpha reliabilities for the respective sub-scales were $.90, .88, .87, .76, .74, .69$, and .75 . In this study, the Cronbach alpha coefficient was found to be .94 , and the Coefficient alphas for the sub-scales ranged from .78 to .92 .

Mathematics Attitude Scale (AŞKAR, 1986): This instrument was a 20-item, balanced, one-dimensional, Likert-type scale, and assessing students' mathematics attitudes. This is a commonly used mathematics attitude scale in Turkey. The Cronbach alpha coefficient has been reported as .96. In the present study, the Cronbach alpha coefficient of this scale was .95 .

Personal Information Form: This information form is used to get independent variables, namely gender, class level, education level of parents, family income, and location of hometown, mathematics grades, perceived importance of subjects taught in mathematics courses (PIM), perceived ability level to learn mathematics (PAM), and perceived success level in mathematics (PSM). In this form, the three items (PIM, PAM, PSM) designed to measure the perceptions of the participants are also included. To assess PIM, the following question, "Do you think the subjects taught in mathematics courses are important?" was asked. The participants were asked to express their beliefs using a five-point scale $(1=$ not at all important to 5 = very important). To assess PAM, the following question, 'Could you assess your ability to learn mathematics?' was asked. They were asked to express how they perceive themselves using a five-point scale $(1=$ very low ability to $5=$ very high ability). To assess PSM, the following question, "Could you assess your success in mathematics lessons?" was asked. They were asked to express how they view themselves using a five-point scale (1 = very low success to $5=$ very high success). There was only one common mathematics course taken by all the participants involved in the study. Consequently, the grades in this compulsory mathematics course were used to assess mathematics achievement. Family incomes were categorized into three groups, namely low (less than $750 \mathrm{TL}$ ), moderate (750$1500 \mathrm{TL}$ ), and high (more than $1500 \mathrm{TL}$ ), according to the minimum monthly wage determined by the Turkish government. 


\subsection{Data collection and analysis}

Mathematics anxiety was measured on a four point rating scale ranging from 1 ( $I$ would feel highly anxious) to 4 (I would not feel anxious). High scores on the MAST indicate higher levels of MA. The mathematics attitude was measured on a five point rating scale. Positive elements on the scale are assigned with numerical values ranging from 1 (strongly disagree) to 5 (strongly agree). For the negative items, the scoring was reversed. Higher scores on the scale indicate higher levels of attitudes toward mathematics. The Statistical Procedures for Social Sciences (SPSS) 17.0 (SPSS Inc, 2008) was used to code and analyze the data. It was screened for the assumptions of parametric statistics. Normality and homogeneity of variances were tested at a multivariate level. Descriptive statistics and intercorrelations on the study variables were computed. In this study, independent samples $t$-test, one-way ANOVA, Tukey HSD post hoc analysis, and Pearson's product-moment correlation were conducted.

\section{Results}

\subsection{What is the mathematics anxiety (MA) level of pre-service elementary school (PES)} teachers?

The study found that the lowest and highest attained scores for the MA of PES teachers on the MAST scale were 39 and 130, respectively. It was also determined that the range between the lowest and highest score were 91, the mean and standard deviation of the MAST scores were $M=68.94$, and $S D=18.08$. The mean MA score on the scale falls in the low range, so it can be said that Turkish PES teachers have a low level of MA.

\subsection{Do the MA scores differ significantly according to gender, class level, PIM, PAM, and PSM?}

Independent samples $t$-test were used to determine if there was a significant difference in MA scores in terms of gender, class level, PIM, PAM, and PSM variables. 
Table 2 - Results of the independent samples $t$-test related to gender, class level, PIM, PAM and PSM

\begin{tabular}{llcccccc}
\hline Variables & & $n$ & $M$ & $S D$ & $d f$ & $t$ & $p$ \\
\hline Gender & Female & 244 & 70.36 & 17.68 & 478 & -1.749 & .081 \\
& Male & 236 & 67.47 & 18.41 & & & \\
Class Level & Freshman & 248 & 72.04 & 18.44 & 478 & 3.943 & .000 \\
& Senior & 232 & 65.62 & 17.10 & & & \\
PIM & Low & 155 & 77.52 & 21.55 & 478 & 7.591 & .000 \\
& High & 325 & 64.85 & 14.51 & & & \\
PAM & Low & 224 & 77.00 & 18.85 & 478 & 10.050 & .000 \\
& High & 256 & 61.88 & 14.01 & & & \\
PSM & Low & 250 & 75.94 & 18.59 & 478 & 9.651 & .000 \\
& High & 230 & 61.33 & 14.00 & & & \\
\hline \multicolumn{7}{c}{ Source: developed by the authors } \\
\end{tabular}

As seen in Table 2, although the MA score of the female PES teachers $(M=70.36, S D$ $=17.68)$ was higher than male PES teachers $(M=67.47, S D=18.41)$, the results of the independent samples $t$-test showed that there was no significant difference between the MA scores of female and male PES teachers $[t=-1.749, d f=478, p>.05]$. Table 2 also shows that the MA score of the freshman PES teachers $(M=72.04, S D=18.44)$ was higher than the senior PES teachers $(M=65.62, S D=17.10)$, who had not yet taken the mathematics method courses. It was found a significant difference between the MA scores of the freshmen and senior PES teachers $[t=3.943, d f=478, p<.01]$. So, it can be assumed that the higher the class level, the lower will be the PES teachers' MA score.

As seen in Table 2, there were also significant differences between the MA scores of the low and high PSM group $[t=7.591, d f=478, p<.01]$, between the low and high PIM group $[t=10.050, d f=478, p<.01]$, and between the low and high PAM group $[t=9.651, d f$ $=478, p<.01]$ in favor of the lower of MA score.

\subsection{Do the MA scores of PES teachers differ significantly according to the education level of parents, family income, location of hometown, and mathematics achievement?}

A one-way ANOVA was used to determine if there was a significant difference in the MA scores of the PES teachers in terms of the education level of parents, family income, location of hometown, and mathematics achievement. Tukey's HSD test was conducted as a post-hoc analysis for multiple comparisons.

As seen in Table 3, results of the ANOVA revealed that there was no significant difference among the MA scores of PES teachers in terms of theirs mothers' education levels 
$[F(4-479)=1.500, p>.05]$ and their fathers' education levels $[F(4-479)=1.855, p>.05]$.

Therefore, it can be said that the education levels of parents do not have a significant impact on the MA scores of PES teachers. The results of the ANOVA also revealed no significant differences among the MA scores of the PES teachers in terms of hometown locations [ $F$ (2$479)=.739, p>.05]$ and family income variables $[F(2-479)=2.149, p>.05]$. Consequently, it can be assumed that both the location of hometown and family income had no significant impact on the MA scores of PES teachers.

Table 3 - Results of the ANOVA related to ELM, ELF, and location of hometown, family income and mathematics achievement

\begin{tabular}{|c|c|c|c|c|c|c|}
\hline Variables & $n$ & $M$ & $S D$ & $d f$ & $F$ & $p$ \\
\hline \multicolumn{7}{|l|}{ Education Level of Mother (ELM) } \\
\hline Illiterate & 24 & 73.87 & 19.01 & $4-479$ & 1.500 & .201 \\
\hline Primary School & 200 & 69.86 & 17.52 & & & \\
\hline Secondary School & 63 & 68.30 & 18.41 & & & \\
\hline High School & 119 & 69.21 & 18.86 & & & \\
\hline Higher Education & 74 & 64.97 & 17.43 & & & \\
\hline \multicolumn{7}{|l|}{ Education Level of Father (ELF) } \\
\hline Illiterate & 124 & 72.40 & 18.69 & $4-479$ & 1.855 & .117 \\
\hline Primary School & 245 & 67.77 & 17.46 & & & \\
\hline Secondary School & 44 & 69.29 & 16.37 & & & \\
\hline High School & 53 & 65.67 & 19.79 & & & \\
\hline Higher Education & 14 & 70.07 & 19.40 & & & \\
\hline \multicolumn{7}{|l|}{ Location of Hometown } \\
\hline Village & 114 & 70.51 & 17.99 & $2-479$ & .739 & .478 \\
\hline Town & 142 & 69.16 & 18.44 & & & \\
\hline City & 224 & 68.01 & 17.91 & & & \\
\hline \multicolumn{7}{|l|}{ Family Income } \\
\hline Low $(<750 \mathrm{TL})$ & 266 & 70.37 & 18.12 & $2-479$ & 2.149 & .118 \\
\hline Moderate (750 TL-1500 TL) & 135 & 67.83 & 17.32 & & & \\
\hline $\operatorname{High}(>1500 \mathrm{TL})$ & 79 & 66.00 & 18.91 & & & \\
\hline \multicolumn{7}{|l|}{ Mathematics Achievement (1-4) } \\
\hline Low $(<2)$ & 72 & 85.58 & 19.38 & $2-479$ & 61.733 & .000 \\
\hline Moderate (2-3) & 208 & 70.54 & 16.74 & & & \\
\hline $\operatorname{High}(>3)$ & 200 & 61.28 & 14.12 & & & \\
\hline
\end{tabular}

Source: developed by the authors

Table 3 shows that the MA scores of the PES teachers decreased according to the level of their mathematic achievement. Results of the ANOVA revealed that there was a significant difference among the MA scores of the PES teachers in terms of the levels of mathematics achievement $[F(2-479)=61.733, p<.01]$. Tukey HSD post hoc analysis indicated that the low mathematics achievement groups $(M=85.58, S D=19.38)$ scored significantly higher than moderate (mean difference $=15.04, S E=2.20, p<.01$ ) and higher mathematics achievement groups (mean difference $=24.30, S E=2.21, p<.01$ ). Tukey post hoc analysis 
also showed that the moderate mathematics achievement group scored $(M=70.54, S D=$ 16.74) significantly higher than the high mathematics achievement group (mean difference $=$ 9.26, $S E=1.59, p<.01)$.

\subsection{Is there a significant relationship between MA and both mathematics achievement and mathematics attitudes?}

The Pearson's product-moment correlation was used to determine if there was a significant relationship between mathematics anxiety (MA) and both mathematics attitudes and mathematics achievement.

Table 4 - The relationship among the mathematics anxiety (MA), mathematics attitude and mathematics achievement

\begin{tabular}{|c|c|c|c|}
\hline Variable & Mathematics Anxiety & $\begin{array}{l}\text { Mathematics } \\
\text { Attitude }\end{array}$ & $\begin{array}{l}\text { Mathematics } \\
\text { Achievemen }\end{array}$ \\
\hline $\begin{array}{l}\text { Mathematics Anxiety (MA) } \\
(n=480, M=68.94, \mathrm{~S} D=18.08)\end{array}$ & 1.000 & $-.553 * *$ & $-.427 * *$ \\
\hline $\begin{array}{l}\text { Mathematics Attitude } \\
(n=480, M=71.01, \mathrm{~S} D=18.68)\end{array}$ & & 1.000 & $.405 * *$ \\
\hline $\begin{array}{l}\text { Mathematics Achievement } \\
(n=480, M=2.55, S D=.82)\end{array}$ & & & 1.000 \\
\hline
\end{tabular}

As seen in Table 4, a medium significant negative correlation was found between mathematics attitudes $(M=71.01, S D=18.68)$ and MA $(M=68.94, S D=18.08)[r=-0.553$, $p<.01]$. This finding implies that as mathematics attitudes scores decrease, mathematics anxiety scores increase. Pearson's product-moment correlation also revealed a similar relationship between mathematics achievement and MA, but this relationship was moderate in magnitude. This research revealed a significant negative and medium level correlation between MA $(M=68.94, S D=18.08)$ and mathematics achievement $(M=2.55, S D=0.82)$ $[r=-0.427, p<.01]$. Accordingly, it can also be said that less successful the students are, the more likely they are to have MA. In addition, significant positive and medium level correlations were found between mathematics attitudes $(M=71.01, S D=18.68)$ and mathematics achievement $(M=2.55, S D=0.82)[r=0.405, p<.01]$. The determination coefficients $\left(r^{2}\right)$ indicated that while $30.6 \%$ of the variance of MA scores can be explained by mathematics attitudes, only $18.2 \%$ of the variance of MA scores can be explained by mathematics achievement. 


\section{Discussion}

Many researchers investigated MA and attitudes toward mathematics. Although they had different comprehensions and reached conflicting results, they emphasized similar and common arguments about the negative consequences. For instance, Martinez (1987) cited math-anxious teachers as a cause of math-anxious students. Similarly, Vinson (2001) identified negative attitudes toward mathematics as a cause of negative results in mathematics. Researchers found these constructs worth investigating, and they studied not only their prevalence, dimensions, and correlation, but also their causes and effects. In addition, they provided recommendations to reduce or to eliminate their negative consequences.

In this study, it is revealed that the MA scores of pre-service elementary school (PES) teachers $(n=480, M=68.94, S D=18.08)$ are similar, but a bit higher than the scores of the PES teachers $(n=84, M=66.60, S D=13.49)$ in a recent study conducted by Üldaş $(2005)$. Previous studies demonstrated that MA was more likely to occur among females than males (BETZ, 1978; HEMBREE, 1990; STENT, 1977). Similarly, this study indicated that the mean score was higher for females than for males, although the difference between their mean was not significant. The result is in consonance with that of Widmer and Chavez (1982), who found no significant relationship between gender and MA among elementary school mathematics teachers. These results may be due to the fact that the present pre-service education has been developed according to scientific research results. As a result, the current comprehensions and implementations in the present pre-service education system help narrow gender differences and reduce MA. There is a need, however, to carefully interpret the results due to the limitations that exist in the research, such as the limited sample and the self-report nature of the study. Furthermore, as Gresham (2008) stated, even if the anxiety is low, it is not possible to say that they are free from it. It can be said that education faculties in Turkey are unaware of MA and do not attempt to provide the necessary counseling services or intervention programs for math anxious students. Therefore, mathematics educators and counselors should identify math-anxious teacher candidates in close cooperation and then provide the necessary support and counseling for them.

This study indicates that freshmen are more inclined to have MA than the seniors. Alternatively, it can be assumed that MA is reduced at the end of the pre-service education. This may be explained by the fact that seniors have taken the mathematics method course for two consecutive semesters. Parallel findings about the efficacy of the mathematics method 
courses on MA have been reported by several researchers (HARPER; DAANE, 1998; LYNCH, 1994; SOVCHIK; MECONI; STEINER, 1981; VINSON, 2001). This conclusion may also provide support to the aforementioned comment that the present pre-service education system helps in reducing MA. It may be too early to applaud the current methods, because of the lack of data displaying the cases of highly math-anxious teacher candidates. Although the total MA scores were reduced at the end of pre-service education, there is still need for a longitudinal research, to follow highly anxious candidates and to evaluate whether meaningful changes have actually occurred in their specific situations.

Aiken (1974) expounded on the perceived importance or value of mathematics in attitudes toward mathematics. Hadfield and McNeil (1994) proposed lack of confidence in mathematical ability and lack of perceived usefulness of mathematics as the intellectual causes of MA. Similarly, Bonnstetter (2007) also assessed feelings about mathematics in one of the six categories, to explain changes in the levels of MA. Combining these theoretical assumptions about mathematics, as related to MA in a single study, and investigating whether MA differed according to them is the main aim of this study. To do so, the perceived importance of mathematics is investigated by PIM, the perceived ability level to learn mathematics is investigated by PAM, and the perceived success level in mathematics is investigated by PSM. As pointed out in the literature, this study reveals that these perceptions are important in terms of MA; that is, PIM and PAM have a moderate effect, and PSM has a great effect. Additionally, MA scores differed significantly with respect to their intensity. Similarly, Hembree (1990) found a significant negative relationship between the high and average groups according to the ability based upon MA scores. In accordance with this result, pre-service elementary mathematics teachers differed in terms of PAM in this study.

The socioeconomic status could be regarded as representative of a variety of factors, including parental education, family income, and location of hometown, which could influence MA. In this study, the MA scores did not differ significantly according to these factors. It was revealed that the socioeconomic status of PES teachers did not have a considerable impact on MA. This may be a result of the relative independence of the PES teachers from their parents, due to the extra income and new living environments, such as the dormitory and campus life. Furthermore, parental education can no longer influence them, because, as it can be gathered from Table 1, most PES teachers are more educated than their parents. Extra income, such as bursaries and grants, fill the gap of income differences. In addition, shared campus life provides similar life experiences. On the other hand, educators and counselors must be very careful of the effects these variables have on MA at the primary 
and secondary grades. As a matter of fact, a few previous studies support this warning (ARIKAN, 2004; ENGELHARD, 2001; VANN, 1992).

This study indicates that there is a tendency for students with negative attitudes toward mathematics and low achievers to possess higher levels of MA. Tapia and Marsh (2004) designed a mathematics attitudes scale and measured MA in a questionnaire with four ratings. They found that although the main effect of gender was insignificant, with a small effect size, the main effect of MA was significant with a large effect size on attitudes towards math. Similarly, Gresham (2008) concluded that the highest levels of MA were encountered among pre-service teachers with negative attitudes toward mathematics. Hembree (1990) and Ma (1999) reported significant negative correlations between mathematics achievement and MA in their meta-analysis studies. In a comparative study, Engelhard (2001), by using a five-item scale developed for the Second International Mathematics Study [SIMS], also reported significant negative relationships between mathematics achievement and MA, in a sample of adolescents from The United States $(r=-.24)$ and Thailand $(r=-.14)$, who participated in the SIMS. Woodard (2004) also found a significantly low correlation $(r=-.20)$ between mathematics achievement and MA in a sample of 125 students enrolled in a community college when using the exit examination scores of mathematics. Similarly, it was reported a significant negative and medium level correlation between MA and mathematics achievement $(r=-0.43)$. These studies agree with the present study, which has found that, as MA scores increase, achievement scores decrease. In addition, this study reveals that MA differed significantly according to students' levels of achievement in mathematics. Engelhard (2001) stated that the direct effect of MA on achievement may be small, but the indirect effects such as mathematics avoidance and negative attitude toward math-related activities make it necessary to give it further consideration.

Previous researches stated that some teachers had MA and transferred it to the students (BALOĞLU, 2001; HARPER; DAANE, 1998). On the other hand, some argued that the fact that the forthcoming teachers of this study, who will be responsible for educating future generations, have low levels of MA, is a positive development that gives hope for the future. As a result of the aforementioned findings, we claim that the present pre-service elementary teacher education system has a positive impact on reducing MA. By being both less-anxious and well-prepared about the contemporary learner-centered approaches, the prospective teachers have an important role to play for future generations.

It is shown in several studies that the MA of PES teacher is significantly reduced when the emphasis is placed on understanding (BURSAL; PAZNOKAS, 2006; HEMBREE, 1990; 
TOBIAS, 1998; VINSON, 2001). Gresham (2007) found a statistically significant reduction in the MA scores of 248 early childhood/elementary education pre-service teachers who completed a methods course that emphasized the use of manipulative and concrete learning of the mathematical content. Therefore, the concepts should be related to the learners' prior experiences and be constructed, connected, applied, and transferred to the learners' relevant and meaningful contexts, with active participation and cooperation. Effective mathematics instruction is a widespread suggestion in MA literature and many strategies are also provided to accomplish this in these literatures.

There are many sample intervention techniques to reduce or eliminate MA. Townsend, Moore, Tuck, and Wilton (1998), mentioned some successful intervention techniques, such as systematic desensitization, stress-inoculation training, anxiety management, and systematic rational restructuring for math anxious university students (WADLINGTON; AUSTIN; BITNER, 1992; FOSS; HADFIELD, 1993; SCHNEIDER; NEVID, 1993; VANCE; WATSON, 1994). As a meta-analytic result, Ma (1999) revealed that screening and treatment programs should be provided for upper elementary grades. In addition, the meta-analytic studies revealed that out-of-class psychological treatments and behavioral therapy are more efficient than classroom intervention programs (BEASLEY; LONG; NATALI, 2001). In Turkey, however, counseling is considered as a profession mainly responsible for planning and delivering counseling to high school students (DOĞAN, 2000). This is why elementary school teachers need to make further efforts to reduce or eliminate MA, and also to avoid creating negative experiences for the students. For this reason, there is a need to raise the awareness and to educate PES teachers about MA. To this end, some courses such as the course of Guidance, a compulsory course for teacher candidates in Turkey, can be employed in collaboration with the mathematics educators. At the same time, educational administrators need to make available the necessary infrastructure for elementary school counseling to carry out its responsibilities, at the earliest.

\section{Conclusion}

This study aims to reflect the current level of MA among PES teachers and to determine several factors and correlations thought to be influential or important for MA. In conclusion, it was revealed that the MA scores of PES teachers can be interpreted as low and the difference based on gender is not significant. At the end of the pre-service education, seniors are significantly less likely than freshmen to have MA. These results may be accepted 
as promising for the future. Attitudes and perceptions (PIM, PAM, and PSM) related to mathematics are revealed as important factors for MA in pre-service teachers. Conversely, the education level of parents, family income, and location of hometown are not. Therefore, if the PES teachers believe that they can be successful in mathematics and have the ability to accomplish it, and if they understand the importance of mathematics during their pre-service education, there will be more opportunity to prevent or reduce MA. Despite some limitations, it is hoped that the results will provide some insights to revise course requirements and teaching strategies, to plan future intervention programs, and to bring about collaboration between mathematics educators and counselors.

\section{References}

AIKEN, L. R. Two scales of attitude toward mathematics. Journal for Research in Mathematics Education, Reston, Va, v. 5, n. 2, p. 67-71, Mar. 1974.

ARIKAN, G. The relationship between the students' maths anxiety levels and maths achievements levels. 2004. 107 f. Unpublished master's thesis, Institute of Educational Sciences, Gazi University, Ankara. 2004.

AŞKAR, P. Development of a Likert-type mathematics attitude scale. Education and Science, Ankara, v. 11, n. 62, p. 3-36, Apr. 1986.

ATKINSON, R. T. An exploration of the factors relating to the system of mathematics anxiety. 1998. 152 f. Unpublished doctoral dissertation, Faculty of Education, Oklahoma State University, Oklahoma, 1988.

BALOĞLU, M. Overcoming mathematics anxiety. Educational Sciences: Theory \& Practice, Istanbul, v. 1, n.1, p. 59-76, July 2001.

BALOĞLU, M.; KOÇAK, R. A multivariate investigation of the differences in mathematics anxiety. Personality and Individual Differences, Philadelphia, Elsevier B.V., v. 40, n. 7, p. 1325-1335, May 2006.

BATTISTA, M. T. The relationship of mathematical anxiety and mathematical knowledge to the learning of mathematical pedagogy by preservice elementary teachers. School Science and Mathematics, Menasha, v. 86, n. 1, p. 10-19, Jan. 1986.

BEASLEY, T. M.; LONG J. D.; NATALI, M. A confirmatory factor analysis of the mathematics anxiety scales for children. Measurement and Evaluation in Counseling and Development, London, Sage, v. 34, n. 1, p. 14-26, Apr. 2001.

BEKDEMIR, M. The causes of mathematics anxiety in elementary preservice teachers and proposals for decreasing mathematics anxiety. Erzincan University Journal of Faculty of Education, Erzincan, v. 9, n. 2, p.131-144, Dec. 2007.

BESSANT, K. C. Factors associated with types of mathematics anxiety in college students. Journal for Research in Mathematics Education, Reston, Va, v. 26, n. 4, p. 327-345, June 1995. 
BETZ, N. Prevalence, distribution, and correlates of math anxiety in college students. Journal of Counseling Psychology, New York, v. 25, n. 5, p. 441-448. Sept. 1978.

BIRGİN, O.; BALOĞLU, M.; ÇATLIOĞLU, H.; GÜRBÜZ, R. An investigation of mathematics anxiety among sixth through eighth grade students in Turkey. Learning and Individual Differences, Philadelphia, Elsevier B.V., v. 20, n. 6, p. 654-658, Oct. 2010.

BONNSTETTER, R. A follow-up study of mathematics anxiety in middle grades students. 2007. 435 f. Dissertation (Master in Education) - Faculty of Education, University of South Dakota, United States. 2007.

BUHLMAN, B. J.; YOUNG, D.M. On the transmission of mathematics anxiety. Arithmetic Teacher, Reston Va, v. 30, n. 3, p. 55-56, Nov. 1982.

BURSAL, M.; PAZNOKAS, L. Mathematics anxiety and preservice elementary teachers' confidence to teach mathematics and science. School Science and Mathematics, Menasha, USA, v. 106, n. 4, p. 173-179, Apr. 2006.

BYRD, P. A descriptive study of mathematics anxiety: Its nature and antecedents. 1982. $362 \mathrm{f}$. Unpublished doctoral dissertation, Faculty of Education, Indiana University: Bloomington. 1982.

DOĞAN, S. The historical development of counselling in Turkey. International Journal for the Advancement of Counselling, New York, v. 22, n. 1, p. 57-67, Mar. 2000.

ENGELHARD, J. G. Math anxiety, mother's education, and the mathematics performance of adolescent boys and girls: Evidence from the United States and Thailand. The Journal of Psychology, New York, v. 124, n. 3, p. 289-298, May 2001.

EDUCATIONAL RESEARCH AND DEVELOPMENT DIRECTORATE (ERDD). The results of OECD-PISA 2003 Research related to Turkey: Final national report of PISA 2003 Project.

Ankara: Ministry of National Education Press, Turkey, 2005.

FOSS, D. H.; HADFIELD, O. D. A successful clinic for the reduction of mathematics anxiety among college students. College Student Journal, Alabama, v. 27, n. 2, p. 157-165, June 1993.

FRANZ, E. K. E. Knowing about not knowing: A cognitive view of mathematics anxiety. 2005. $205 \mathrm{f}$. Unpublished doctoral dissertation, Faculty of Education, Department of Educational and Counseling Psychology, McGill University, Montreal, Canada. 2005.

GRESHAM, G. A study of mathematics anxiety in pre-service teachers. Early Childhood Education Journal, London, Springer-Verlag, v. 35, n. 2, p. 181-188, Oct. 2007.

GRESHAM, G. Mathematics anxiety and mathematics teacher efficacy in elementary pre-service teachers. Teaching Education, London, v. 19, n. 3, p. 171-184, Nov. 2008.

HADFIELD, O. D.; MCNEIL, K. The relationship between Myers-Briggs personality type and math anxiety among preservice elementary teachers. Journal of Instructional Psychology, Alabama, v. 21, n. 4, p. 375-384, Dec. 1994.

HALAT, E. The views of elementary school teachers on the new elementary school mathematics curriculum. Afyon Kocatepe University Journal of Social Sciences, Afyonkarahisar, v. 9, n. 1, p. 63-88, June 2007. 
HARPER, N. W.; DAANE, C. J. Causes and reduction of mathematics anxiety in preservice elementary teachers. Action in Teacher Education, London, Taylor \& Francis, v. 19, n. 4, p. 29-38, Dec. 1998.

HEMBREE, R. The nature, effects, and relief of mathematics anxiety. Journal for Research in Mathematics Education, Reston, Va, v. 21, n. 1, p. 33-46, Jan. 1990.

HILTON, P. Math anxiety: Some suggested causes and cures: Part 1. The Two-Year College Mathematics Journal, Washington, D.C, v. 11, n. 3, p. 174-188, Sept. 1980.

JACKSON, C. D.; LEFFINGWELL, R. J. The role of instructors in creating math anxiety in students from kindergarten through college. Mathematics Teacher, Reston, Va, v. 92, n. 7, p. 583-586, Oct. 1999.

KELLY, W. P.; TOMHAVE, W. K. A study of math anxiety/math avoidance in preservice elementary teachers. Arithmetic Teacher, Reston, Va, v. 32, n. 5, p. 51-53, Jan. 1985.

LYNCH, G. C. The efficacy of an elementary mathematics methods course in changing preservice elementary teachers' mathematics anxiety. 1994. $273 \mathrm{f}$. Unpublished doctoral dissertation, Faculty of Education, Dalhousie University, Canada. 1994.

MA, X. A meta-analysis of the relationship between anxiety toward mathematics and achievement in mathematics. Journal for Research in Mathematics Education, Reston, Va, v. 30, n .5, p. 520-540. 1999.

MALINSKY, M.; ROSS, A.; PANNELLS, T.; MCJUNKIN, M. Math anxiety in pre-service elementary school teachers. Education, Alabama, v. 127, n. 2, p. 274-279, Jan. 2006.

MARTINEZ, J. G. R. Preventing math anxiety: A prescription. Intervention in School and Clinic, London, Sage, v. 23, n. 2, p. 117-125, Nov. 1987.

MoNE [Ministry of National Education]. Turkish Primary School Mathematics Curriculum. Ankara: Ministry of National Education Press. Turkey, 2005.

NEWSTEAD, K. Aspects of children's mathematics anxiety. Educational Studies in Mathematics, Dordrecht, Holanda, v. 36, n. 1, p. 53-71, Jun. 1998.

POSAMENTIER, A. S.; STEPELMAN, J. S. Teaching secondary school mathematics. 3. ed. New York: Merrill. 1990.

RICHARDSON, F. C.; SUINN, R. M. The mathematics anxiety rating scale: Psychometric data. Journal of Counseling Psychology, Washington, D.C , v. 19, n. 6, p. 551-554, Nov. 1972.

ROSSNAN, S. Overcoming math anxiety. Mathitudes, Florida, v. 1, n. 1, p. 1-4, Jan. 2006.

SCHNEIDER, W. J.; NEVID, J. S. Overcoming math anxiety: a comparison of stress inoculation training and systematic desensitization. Journal of College Student Development, Nashville, v. 34, n. 4, p. 283-288, July 1993.

SOVCHIK, R.; MECONI, L. J.; STEINER, E. Mathematics anxiety of preservice elementary mathematics methods students. School Science and Mathematics, Menasha, v. 81, n. 8, p. 643-648, Dec. 1981.

STENT, A. Can math anxiety be conquered? Change, Abingdon, v. 9, n. 1, p. 40-43, 1977. 
TAPIA, M.; MARSH, G. E. The relationship of math anxiety and gender. Academic Exchange Quarterly, New York, v. 8, n. 2, p. 130-134, July 2004.

TOBIAS, S. Anxiety and mathematics: An Update. Harvard Education Review, Harvard, v. 50, n. 1, p. 63-70, Feb. 1998.

TOWNSEND, M. A. R.; MOORE, D. W.; TUCK, B. F.; WILTON, K. M. Self-concept and anxiety in university students studying social science statistics within a co-operative learning structure.

Educational Psychology, United Kingdom, v. 18, n. 1, p. 41-55, Mar. 1998.

UUSIMAKI, L.; NASON, R. Causes underlying pre-service teachers' negative beliefs and anxieties about mathematics. In: CONFERENCE OF THE INTERNATIONAL GROUP FOR THE PSYCHOLOGY OF MATHEMATICS EDUCATION, $28^{\text {th }}$, 2004, Bergen. Proceedings... Bergen, 2004, v. 4, p. 369-376.

ÜLDAŞ, İ. Development of a mathematics anxiety scale towards teachers and teacher candidates (MAS-T) and an assessment on mathematics anxiety. 2005. $146 \mathrm{f}$. Unpublished master's thesis, Institute of Educational Sciences, Marmara University, Turkey, 2005.

VANCE, W. R.; WATSON, T. S. Comparing anxiety management training and systematic rational restructuring for reducing mathematics anxiety in college students. Journal of College Student Development, Nashville, v. 35, n. 4, p. 261-266, July 1994.

VANN, B. D. N. Mathematics anxiety: Parental anxiety as it relates to anxiety in children. 1992. $156 \mathrm{f}$. Unpublished doctoral dissertation, Faculty of Education, University of Arkansas, United States. 1992.

VINSON, B. M. A comparison of preservice teachers' mathematics anxiety before and after a methods class emphasizing manipulatives. Early Childhood Education Journal, New York, US, v. 29, n. 2, p. 89-94, Dec. 2001.

WADLINGTON, E.; AUSTIN, S.; BITNER, J. The treatment of math anxiety and negative math selfconcept in college students. College Student Journal, Alabama, v. 26, n. 1, p. 61-65, Mar. 1992.

WIDMER, C.; CHAVEZ, A. Math anxiety and elementary school teachers, Education, Alabama, v. 102, n. 3, p. 272-276, Mar. 1982.

WOODARD, T. The effects of mathematics anxiety on post-secondary developmental students as related to achievement, gender, and age. Inquiry, New York, US, v. 9, n. 1, 2004. Retrieved January 21, 2009. Available in: <http://www.vccaedu.org/inquiry/inquiry-spring2004/i-91-woodard.html>. Access in: 17 Jan. 2010.

ZASLAVSKY, C. Fear of math: How to get over it and get on with your life. New Brunswick, NJ: Rutgers University Press, 1994. 